\title{
Variable states
}

\section{Corinna Wu}

\author{
Energy storage can help integrate wind \\ and solar power into the electric grid.
}

$\mathbf{O}$ August 14, 2003, a downed high-voltage power line in Ohio triggered a massive blackout across eight states in the Northeast and throughout Southeastern Canada. A total of 50 million people lost power for up to two days. The episode cost an estimated $\$ 6$ billion and is considered to be the worst electrical system failure in the history of the United States.

The cascade of failures - due to both human error and equipment malfunction-made clear the problems of the United States' aging and balkanized electrical transmission grid. The blackout spurred Congress to pass the Energy Policy Act of 2005, which enforces mandatory reliability standards. Investment in the transmission grid had fallen during the 1980s and 1990s, but after the blackout, funding picked up again.

Against this backdrop, power companies and regulating authorities now have another challenge to face: how to integrate variable and intermittent renewable resources such as solar and wind into the mix. Currently, electricity from non-hydro renewable resources accounts for $3.8 \%$ of the total electricity produced in the United States, according to the U.S. Energy Information Administration. In 2009, half of non-hydro renewable electricity came from wind and less than one percent from solar.

However, that share is set to rapidly increase. Thirty states and the District of Columbia have established Renewable Portfolio Standards, regulations that require the increased production of energy from renewable energy sources. For example, California has set a goal of generating $33 \%$ of its electricity this way by 2020, and New York has set a goal of 30\% by 2015 .

Although wind and solar are attractive because they do not produce greenhouse gases, they also pose difficulties because of their inherent variability. "If you look at wind and solar, their output changes dramatically," said James Misewich, associate laboratory director for basic energy sciences at Brookhaven National Laboratory (Figure 1). The wind waxes and wanes, and the sun assuredly sets every night. Clouds can obscure solar panels, and even if only a portion of a solar array is shaded, it can have a big impact on how much electricity is produced.

If wind and solar must supply a third of the energy generated, the job of meeting changing demand for electricity throughout the day becomes much more difficult. Power plant operators must meet the net load - the difference between user demand and this highly variable renewable output - by scheduling power generation from conventional sources.
One strategy that can help manage that net load variability is the use of storage technologies, including advanced batteries and superconducting magnetic energy storage (Figure 2). Storing electricity generated during periods of low demand-for example, when the wind blows at night - allows that energy to be deployed during periods of high demand, such as in the middle of the afternoon when households have their air conditioning turned on.

For storing energy in bulk, pumped hydroelectric power and "compressed air energy storage" (CAES) technologies can store hundreds of megawatts of power in a single system. The global capacity of pumped hydro is more than 95 gigawatts, with 20 gigawatts operating in the United States, according to an IEEE Power \& Energy Magazine article by Bradford Roberts, power quality systems director at $\mathrm{S} \& \mathrm{C}$ Electric Company and executive director of the Electricity Storage Association. Both pumped hydro and CAES require lots of space, so they are not feasible for all locations.

For materials scientists, a lot of potential research for grid-level energy storage lies in developing advanced battery technologies. "The battery work that's out there is really focused on transportation storage, which has different boundary conditions," said Misewich, who co-chaired an American Physical Society committee on integrating renewable energy into the grid. "If you've got a Chevy Volt, you want [the battery] to be lightweight. That's critical. But if you're designing something for a substation, or to go near a solar panel or a wind turbine, it's stationary."

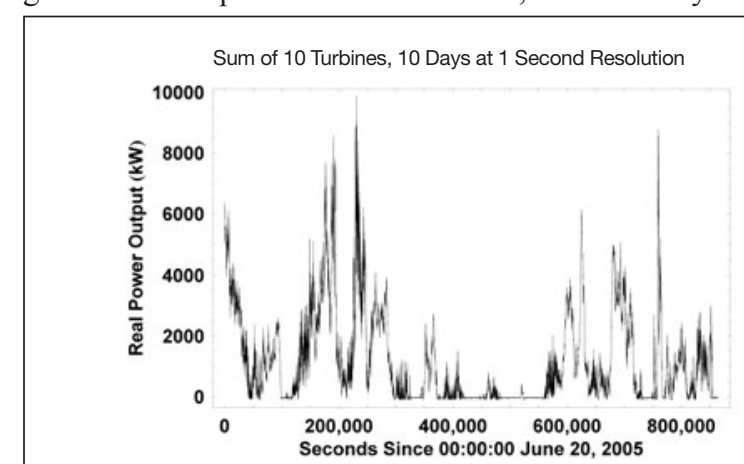

Figure 1. The second-by-second variability in power output from 10 wind turbines over a 10-day period. Source:

J. Apt, Journal of Power Sources 169, 369-374 (2007).

Reprinted with permission from Elsevier. 
A utility-scale battery system would need to be reliable, though, and last on the order of decades. In contrast, batteries for consumer electronics or vehicles generally get replaced every few years. Researchers are considering several different battery chemistries for storing electricity generated by renewable resources.

Lead-acid batteries are too heavy for electric vehicle applications, but they could serve as a low-cost solution for utility power storage. Their big drawback is limited cycling capacity caused by a buildup of lead sulfate on the electrodes. Advanced lead-acid batteries solve that problem. "Adding as much as $40 \%$ of activated carbon to the negative electrode composition increases the battery's life," Roberts writes. "This extended life coupled with lower costs will lead storage developers to revisit lead-acid technology for grid applications."

Sodium sulfur batteries operate at a high temperature and consist of molten sodium and molten sulfur electrodes separated by a ceramic electrolyte. They have a high energy density, high efficiency, and long cycle life. Japan has more than 270 megawatts of storage in sodium sulfur batteries. Additional projects planned in Japan, the United States, and Europe will increase that capacity.

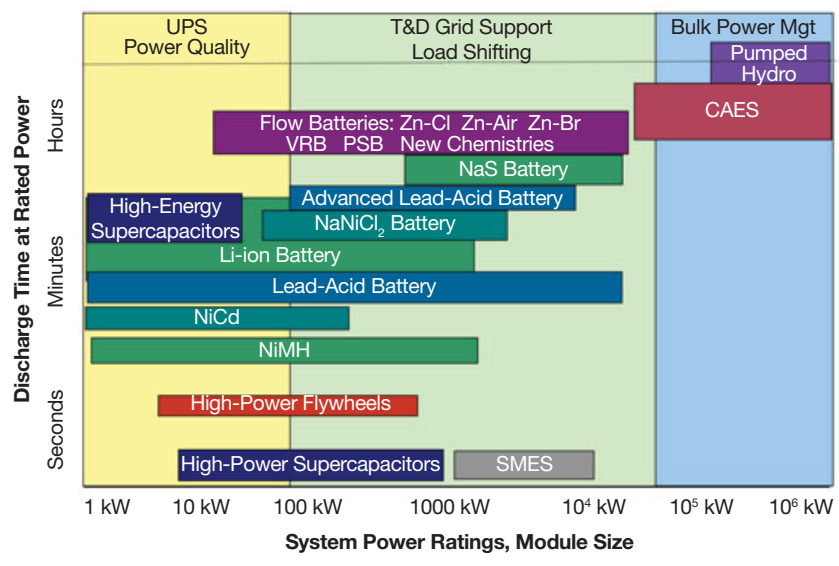

Figure 2. A comparison of grid-level energy storage technologies. UPS, uninterruptible power supply; T\&D, transmission and distribution. Source: Electric Power Research Institute.

Flow batteries, early in their development, are a combination of battery and fuel cell technology. Two liquid electrolytes move through the cell past a proton-exchange membrane and are collected to be reused in the reverse direction. The capacity of a flow battery is limited only by the size of the tanks that hold the electrolytes. Vanadium redox and zinc bromide are two chemistries that are being developed for utility applications.

Although the batteries in electric cars are not designed for gridlevel storage, they could collectively act as distributed storage for electricity generated during off-hours. Most electric cars would probably get charged at night, when their owners are asleep and electricity is less expensive. In grid-to-vehicle applications, the stored electricity would be fed back to the grid when needed.
Superconducting magnetic energy storage (SMES) systems have been used since the 1970s, mostly to release short bursts of energy to smooth out fluctuations in the power supply. A SMES device stores energy in the magnetic field of a superconducting coil, which is charged or discharged by increasing or decreasing the current in the coil, respectively. Scaling up the size of the coil increases the capacity. Researchers at Brookhaven, SuperPower Inc., ABB Inc., and the University of Houston received a grant from the Advanced Research Projects Agency-Energy (ARPA-E) in 2010 to develop an advanced large-scale SMES system for long-term energy storage.

Unlike batteries, SMES systems can be cycled infinitely and provide instantaneous power, which makes them an attractive solution for power plants. Though the concept is not new, scaling up a SMES device for grid-level storage poses technical challenges. "The thing we want to build has to carry a very large amount of energy and use a very high field," said Qiang Li, head of the Advanced Energy Materials Group at Brookhaven. SMES systems have the potential to store a gigawatt of energy for daily load leveling, according to an analysis by the Research Association of Superconducting Magnetic Energy Storage in Japan. Japan has spearheaded a national project to develop SMES for power system control since 1991.

During its third round of ARPA-E grants, the U.S. Department of Energy funded 12 projects for Grid Scale Rampable Intermittent Dispatchable Storage (GRIDS), ranging from CAES to flow batteries to SMES. Meeting the technological challenges to pass a $30 \%$ threshold, Renewable Portfolio Standard will require this sort of additional research and investment, according to the committee report from the American Physical Society, Integrating Renewable Electricity on the Grid. "Without such investments, it is unlikely that all the required mandates can be met," the authors state.

Storage is just one approach to managing energy from variable and intermittent renewable resources, and it might not be the most cost-effective. "One of the big challenges with energy storage is that it is fairly expensive, so it's unclear - at least with the existing technologies — what the cheapest method of integrating renewables is," said Paul Denholm, senior energy analyst at the National Renewable Energy Laboratory in Golden, Colo. "A lot of studies indicate that the least expensive way of integrating renewables is to increase the flexibility of the existing power system - change some ways that we operate the grid so that we can exchange power over larger areas."

Currently, there are 130 different balancing authorities, control areas defined by the Federal Energy Regulatory Commission, and sharing energy between them is not easy. Studies have shown that "the first thing we should do is have better cooperation," Denholm said. "We should just share energy more. When I've got more energy than I need, I'll sell it to you, and when I don't have as much energy as I need, I'll buy it from you. Having those kinds of cooperative agreements would enable greater use of renewables." Also, transmission lines would need to be built to link the Eastern, Western, and Texas Interconnections - the three separate grids that cover the United States. 